\title{
2009/1
}

Forecasting the direction of policy rate changes:

The importance of ECB words

Carlo Rosa 
CORE

Voie du Roman Pays 34

B-1348 Louvain-la-Neuve, Belgium.

Tel (32 10) 474304

Fax (32 10) 474301

E-mail: corestat-library@uclouvain.be http://www.uclouvain.be/en-44508.html 


\title{
CORE DISCUSSION PAPER
}

$2009 / 1$

\section{Forecasting the direction of policy rate changes: The importance of ECB words}

\author{
Carlo ROSA ${ }^{1}$
}

January 2009

\begin{abstract}
This paper evaluates the predictive power of different information sets for the European Central Bank (ECB) interest rate setting behavior. We employ an ordered probit model, i.e. a limited dependent variable framework, to take into account the discreteness displayed by policy rate changes. The results show that the forecasting ability of standard Taylor-type variables, such as inflation and output gap, is fairly low both insample and out-of-sample, and is comparable to the performance of the random walk model. Instead by using broader information sets that include measures of core inflation, exchange rates and monetary aggregates, the accuracy of the forecasts about ECB future actions substantially improves. Moreover, ECB rhetoric contributes to a better understanding of its policy reaction function, and ECB statements complement the information contained in actual macro figures. Finally, we find that that the ECB has been fairly successful in educating the public to anticipate the overall future direction of its monetary policy, but has been less successful in signaling the exact timing of rate changes.
\end{abstract}

${ }^{1}$ Université catholique de Louvain, CORE, B-1348 Louvain-la-Neuve, Belgium; CEP, London, U.K. and IfW, Kiel, Germany. E-mail: carlo.rosa@uclouvain.be

I thank seminar participants at the London School of Economics, and especially Luc Bauwens, Gianluca Benigno, Charles Goodhart and Paul Mizen for comments, and Giovanni Verga for discussions on this and related topics.

This paper presents research results of the Belgian Program on Interuniversity Poles of Attraction initiated by the Belgian State, Prime Minister's Office, Science Policy Programming. The scientific responsibility is assumed by the author. 



\section{Introduction}

What is the information required to make accurate predictions of the future most likely European Central Bank (henceforth ECB) policy rate change? Are Taylor-type macroeconomic variables enough or in practice does the ECB use a wider variety of information that also includes survey data, exchange rates and monetary aggregates? Moreover, does central bank communication provide complementary or substitutable information with respect to macroeconomic variables? This paper attempts to answer these questions empirically by comparing the forecasting performance of different information sets.

A monetary policy rule describes the systematic relationship between the central bank's policy rate and macroeconomic variables. Estimating a reaction function is interesting for two main reasons. First, it is a useful tool to forecast future policy rates. Second, by providing explicitly one equation of the macroeconomic system, the monetary policy rule "closes" the general equilibrium macro-econometric model of the economy and thus it allows to simulate policy experiments. The value added of this study to the empirical monetary policy literature is to evaluate the ECB's empirical reaction function in a limited dependent variable framework that take better into account the discreteness displayed by policy rate changes compared to the standard modeling of the operational rate as a continuously adjusting variable. Moreover, we employ various real-time information sets to predict the direction of ECB monetary policy, where the policy rate change could be "upwards", "downwards" or "no change". In particular, we show that ECB rhetoric contributes to a better understanding of its policy reaction function, and its statements complement the information contained in actual macro figures. This represents a step forward in the existing literature that mostly focuses on the estimation of monetary policy rules using a small set of ex-post realized macroeconomic variables.

The main findings of the paper can be summarized as follows. First, the predictive ability of standard Taylor-type variables (Taylor, 1993) is fairly low both in-sample and out-of-sample, and is comparable to the performance of the random walk model. More specifically, we find that policy rates are closely tied to survey data, while policy responses to the real-time estimate of the output gap are weak and not significantly different from zero once we control for survey data. Moreover, the use of broader information sets that include core inflation, producer price inflation, exchange rates and monetary aggregates improves substantially the forecasting ability of the direction of future ECB policy rate changes.

Second, the tone of ECB statements turns out to contain relevant information to correctly predict the ECB future actions. In other words, central bank communication provides complementary, rather than substitutable, pieces of information with respect to macroeconomic variables.

By estimating monetary policy rules, this paper is part of the large literature on empirical reaction functions. In the interest of space, below we focus on papers estimating the ECB's policy reaction function 
and using only euro area data from 1999. ${ }^{1}$ First, there are studies (among others Carstensen and Colavecchio, 2006, Fourçans and Vranceanu, 2004, and Sauer and Sturm, 2007) that estimate the ECB's policy reaction function by employing a Generalized Method of Moments (GMM) and adopting a Taylor-type specification. We extend this strand of the literature by employing a limited dependent variable framework that better takes into account the discreteness of policy rate changes. Moreover, by using real-time macroeconomic data, rather than ex-post and revised data (Orphanides, 2001 and Coenen, Levin and Wieland, 2005), we do not have endogeneity issues. Some limited work (Carstensen, 2006, and Gerlach, 2007) has been undertaken to employ a limited dependent variable econometric method to estimate empirical reaction functions for the ECB. The present paper also estimate the ECB reaction function by using an ordered probit model, and goes one step further by analyzing the predictive ability both in-sample and out-of-sample of different information sets. The findings of this study are important to improve our understanding of actual monetary policymaking in the euro area for the sample period 1999-2007.

By looking at the importance of ECB words to predict its future policy actions, this paper is also related to the rapidly expanding literature on central bank communication (see Blinder et al., 2008, for a survey), reflecting the increased importance communication aspects have gained in the conduct of monetary policy. Two recent contributions analyse the role of central bank announcements to better understand its policy deeds, as we do in this study. First, Jansen and De Haan (2008) examine the usefulness of statements made by members of the ECB Executive Board, national (of the euro-zone) central bank presidents, and high-level policymakers of the German Bundesbank to predict the ECB policy decisions during the sample period 1999 to 2002. Given that the ECB follows a collegial communication approach, in the present paper we focus on the introductory statements made by the ECB President during the monthly press conference for the sample 1999 to 2007 . The contents of the monthly press conference should better reflect the views of all ECB Governing Council members compared to the declarations made by national central bankers. Indeed, contrary to Jansen and De Haan (2008), we find that the tone of central bank statements is an important explanatory variables of futures changes in the ECB main refinancing rate. Second, Rosa and Verga (2007) assess the consistency and effectiveness of ECB communication, and as a by-product the information content of its rhetoric (see also Heinemann and Ullrich, 2007). The present paper shares the finding that ECB words provide complementary, rather than substitutable information with respect to macroeconomic variables to correctly predict its future deeds. And it goes one step further by investigating the ECB reaction function and performing a comprehensive sensitivity analysis, such as computing out-of-sample predictions, considering different forecasting horizons, and controlling for a wider set of macroeconomic variables. Moreover, the sample period used in this study is 1999 - 2007 rather than 1999 - 2004, and the predictive accuracy is

\footnotetext{
${ }^{1}$ Gerlach and Schnabel (2000), Gerdesmeier and Roffia (2003) and Ullrich (2003) study the behaviour of a "fictitious" European monetary authority prior to the start of Stage Three of the EMU (i.e. before 1999) by using aggregated euro area data. A very detailed list updated until July 2000 of technical and descriptive research papers on monetary policy rules can be found at www.stanford.edu/ johntayl/PolRulLink.htm.
} 
measured by employing the Henriksson and Merton's (1981) criterion, instead of only the corrected classification approach.

The remainder of the paper is organized as follows. Section 2 starts by discussing the ordered probit model. Section 3 describes the choice of the data. Section 4 contains the estimates of simple instrument monetary policy rules for the ECB, and compares the ability of different information sets to predict both insample and out-of-sample the direction of future policy rate changes. Section 5 concludes.

\section{Econometric framework: ordered probit}

Since policy rates do not move most of the time, and when they change they do so by a discrete amount (usually by 25 or 50 basis points, see Table 1), the ordered probit estimation method (Vanderhart, 2000 and Ruud, 2000, chapter 27) takes better care of these intrinsic characteristics of the data compared to standard time series techniques, such as GMM. Moreover, by using real-time predetermined data, i.e. data actually available to the ECB Governing Council members at the time of their policy rate decision, we do not have any endogeneity issue.

\section{[Insert Table 1 about here]}

We assume that the ECB defines its target policy rate, $i_{t+1}^{*}$, on the basis of a smoothing adjustment towards an interest rate, $i_{t+1}^{O}$, which is the optimal rate of the fully specified model guiding the decisions of the ECB Governing Council:

$i_{t+1}^{*}=(1-\rho) i_{t+1}^{O}+\rho i_{t}$

$i_{t+1}^{O}=\boldsymbol{X}_{t+1} \boldsymbol{\beta}$

where $\boldsymbol{\beta}$ and $\rho$ are regression coefficients, and $\boldsymbol{X}_{t+1}$ stands for the set of explanatory variables at time $t+1$. In order to cope with the potential non-stationarity of policy rates, ${ }^{2}$ we use as a dependent variable the change in policy rates:

$i_{t+1}^{*}-i_{t}=\boldsymbol{X}_{t+1} \widetilde{\boldsymbol{\beta}}+\tilde{\rho} i_{t}+\varepsilon_{t+1}$

\footnotetext{
${ }^{2}$ Even though the policy rate may be stationary in large samples, Phillips Perron and augmented Dickey Fuller tests cannot reject the presence of a unit root in our sample (results not reported but available upon request). Moreover, Gerlach-Kristen (2003) shows that policy rules estimated in levels, rather than in the Error Correction Model specification, display both parameter instability and poor out-of-sample forecasts. Note that given the first-difference specification of Equation (2), the coefficient of the lagged policy rate (i.e. interest rate smoothing parameter) is $1+\tilde{\rho}$.
} 
where $\widetilde{\boldsymbol{\beta}} \equiv(1-\rho) \boldsymbol{\beta}, \tilde{\rho} \equiv(\rho-1)$ and the error term $\varepsilon_{t+1}$ is assumed to be normally distributed, and subsumes both implementation errors of the ECB and specification errors of the policy reaction function. ${ }^{3}$

Equation (2) cannot be directly estimated, because $i_{t+1}^{*}-i_{t}$ is not observed by market participants, i.e. it is a latent variable. What is observed is the actual direction of policy rate changes, which depends on where the latent variable is relative to a set of threshold values:

$$
\begin{array}{rlrl}
\Delta i_{t+1} & =\{-50,-25\} & \text { if } & i_{t+1}^{*}-i_{t} \leq c_{1} \\
\Delta i_{t+1}=0 & \text { if } & c_{1}<i_{t+1}^{*}-i_{t} \leq c_{2} \\
\Delta i_{t+1}=\{+50,+25\} & \text { if } & c_{2}<i_{t+1}^{*}-i_{t}
\end{array}
$$

where $c_{j}$ is a threshold parameter with $c_{j}<c_{j+1}$ for all $j .{ }^{4}$ Since it is not possible to simultaneously identify the constant term, the limit points $c_{j}$, and the variance of the error term, in this paper we estimate the threshold parameters, and without loss of generality normalize the constant to zero and the variance to one.

The goodness of fit of the ordered probit model can be measured by the pseudo $R^{2}$ statistics, also known as McFadden's likelihood ratio index, which is given by:

pseudo $R^{2}=1-\ln \left(\mathcal{L} / \mathcal{L}^{*}\right)$

where $\mathcal{L}$ stands for the value of the likelihood of the ordered-response model of Equations (2) and (3), and $\mathcal{L}^{*}$ for the value of the likelihood function when there are no time-varying regressors. Note that Equation (4) takes values ranging from 0 and 1 , as the standard $R^{2}$, and the pseudo $R^{2}$ is related to a likelihood ratio test of the null hypothesis that all slope parameters are zero, i.e. $-2 \cdot \ln \left(\mathcal{L} / \mathcal{L}^{*}\right)$. In addition, as a diagnostic check of model misspecification, we compute p-values of the null hypothesis of no first-order autocorrelation in the generalized residuals (Gourieroux, Monfort and Trognon, 1985, page 326).

To compare the predictive ability of different information sets, we also construct two outcome-based measures of the goodness of fit. More specifically, by maximizing the log-likelihood function of the ordered probit model of Equations (2) and (3), we can compute the predicted probabilities of directional changes and the corresponding predicted sign (i.e. the event with maximum probability). Then we cross-tabulate the direction of forecasted changes against observed outcomes in a contingency table. The proportion of correct predictions is the sum of all diagonal terms divided by the total number of observations. However, an high percentage of corrected classification does not always provide enough evidence to claim that the proposed

\footnotetext{
${ }^{3}$ As pointed out by Gerlach (2007), this standard ordered probit specification differs from the dynamic probit formulation estimated by Eichengreen, Watson and Grossman (1985) and Davutyan and Parke (1995), who assume that $\Delta i_{t+1}^{*}$ depends on observables.

${ }^{4}$ Note that the same methodology could also be applied to forecast the next change of the policy rate, rather than simply its sign. The results of this paper continue to hold. However, by using five categories the estimation results of the probabilities of policy rate changes are based on "rare" events, such as a policy rate increase of 50 basis points and a policy cut of 25 basis points (cf. Table 1).
} 
model has a good predicting performance. Indeed, a simple estimator, such as a "stopped-clock" strategy that would be always correct some of the times, in our situation could do very well too, since the sample features a dominant outcome represented by a no change in the policy rate. In order to overcome this problem and thus correctly evaluate the predictive ability of the two reaction function specifications, we also compute a second and more reliable measure of performance originally proposed by Henriksson and Merton (1981), $H M$. This criterion is defined as follows:

$H M \equiv \frac{1}{J-1} \sum_{k=-1}^{+1}\left[\frac{\sum_{t=1}^{T-1} \mathbf{1}\left(\operatorname{sign}\left(l_{t+1}-l_{t}\right)=k\right) \cdot \mathbf{1}\left(\operatorname{sign}\left(i_{t+1}-i_{t}\right)=k\right)}{\sum_{t=1}^{T} \mathbf{1}\left(\operatorname{sign}\left(i_{t+1}-i_{t}\right)=k\right)}-1\right]$

where $J$ is the number of categories that in our case equals three, $\left(\widehat{l_{t+1}-} l_{t}\right)$ stands for the prediction of the future policy rate change, $\mathbf{1}($.$) is the indicator function that takes value one when the event is true and zero$ otherwise, $k \in\{-1,0,+1\}$, and the sign function $\operatorname{sign}(x)$ takes respectively value +1 when $x>0,0$ when $x=0$ and -1 when $x<0$. Henriksson and Merton's measure always lies between $-1 /(J-1)$ and 1 . The measure $M C$ equals zero for a stopped-clock strategy, suggesting that it has zero predictability. A negative value of $\mathrm{MC}$ can be regarded as being inferior to the stopped-clock strategy. On the other hand, a perfect forecasting model has a $\mathrm{MC}$ value of one.

\section{Data}

\subsection{Macroeconomic variables}

We use monthly data for the sample period February 1999 - December 2007, that is since the onset of the ECB operational life. Unless otherwise stated, throughout the paper we use real-time macroeconomic data, rather than ex-post and revised data. In other words, we employ data actually available to the ECB Governing Council members at the time of their policy rate decision. The dependent variable of all the regressions is always the directional change in the official ECB policy rate, i.e. the minimum bid rate for the main refinancing operations of the Eurosystem.

To measure the real economic activity, we use both the output gap and survey data. The empirical literature on monetary policy rules (see for instance Clarida, Gali and Gertler, 2000 and 1998) highlights the role of the output gap to distinguish between medium-term trends and shorter-term cyclical movements in the economy. We estimate potential output from monthly industrial production in three different ways. ${ }^{5}$ We

\footnotetext{
${ }^{5}$ There are usually two approaches to estimate it: a statistical method that can be either univariate or multivariate, and a structural approach based on the specification of a production function (cf. Baxter and King, 1999, Cerra and Saxena, 2000, and ECB Monthly Bulletin, October 2000). Interestingly, economic forecasters (see Sauer and Sturm, 2007) consider alternative measures to assess the position of the business cycle, such as growth-rate cycles (fluctuations in production growth). The industrial production series is taken from the ECB's website. The most pronounced difference
} 
recursively apply (i.e. every month appending a new data point) a deterministic linear and quadratic trending, and Hodrick-Prescott filter (see Hodrick and Prescott, 1997) with smoothing parameter 14,400. In order to have a more reliable estimate, the sample starts in 1994 (to avoid the issues related to the German reunification) instead of simply using EMU data from 1999. The output gap is defined as the difference between industrial production and its fitted linear and quadratic trend (respectively, $x_{t}^{L}$ and $x_{t}^{Q}$ ), or HodrickPrescott filter $\left(x_{t}^{H P}\right)$. There are many indicators to measure business and consumer confidence in the euro area, including Economic Sentiment, EuroCOIN and EuroGrowth. ${ }^{6}$ Since we have three different business cycle indicators that co-move together (see Figure 1), we apply a principal component analysis to summarize their informational contents. The first component, Factor, explains around $93 \%$ of their variability, and is used in the econometric analysis.

[Insert Figure 1 about here]

Given the ECB definition of price stability as "a year-on-year increase in the Harmonized Index of Consumer Price (HICP) for the euro area of below, but close to, 2\%" (ECB, 2003 and 1998b), a natural starting point is represented by headline inflation. We also consider core inflation measures (HICP excluding unprocessed food and energy prices, CoreInfl) and a production price index, ProdPrices. The underlying motivation to target core inflation, instead of the HICP, is as follows. If there is a transitory shock, then optimal monetary policy should not react to it unless it has a permanent impact on prices. Interestingly, the behaviour of the HICP and core inflation indicators have been so far quite different (see Figure 2). Indeed, the correlation between these three measures of price stability is fairly low, and the correlation between CoreInfl and ProdPrices is even negative (-0.429).

\section{[Insert Figure 2 about here]}

We analyze the ECB reaction to additional explanatory variables such as the exchange rate, monetary aggregates, energy prices, and a proxy for financial market risks. The ECB may consider the effects of the exchange rate channel on the monetary transmission mechanism in terms of both net external demand and import prices (cf. Ball, 1999, Batini et al., 2001, and Taylor, 2001). In particular, an appreciation of the home currency reduces inflation both directly (i.e., the price of imported goods decreases with the appreciation of the currency) and indirectly (i.e., it will lower real GDP by switching foreign

\footnotetext{
between revised and real-time data on industrial production is that the latter takes the publication lag into account. To have real-time data on industrial production, we consider a publication lag of three months. For instance, by looking at the actual releasing dates, the latest information on 1 June 2005 was the industrial production for March 2005.

${ }^{6}$ Survey data present three main advantages over more standard measures of real economic activity such as GDP. First, their data are timely released. Moreover, they seem to be leading indicators. Finally, they are less volatile than GDP: these data are usually free from measurement errors and from seasonal and other short-run fluctuations caused by local and sector-specific shocks.
} 
expenditure). For this reason, we use the real annual growth rate of the Euro compared with the US Dollar (measured in US\$ needed to buy $1 €, g E$ ), where a negative value indicates a depreciation of the euro. Two important caveats should be noted. First, since the effects of the exchange rate change will occur with a lag and inflation is determined in a forward-looking fashion (Woodford, 2003, Chapter 3), the ECB response to the exchange rate can already be incorporated in its response to the inflation rate. Second, the ECB concern for the exchange rate does not mean that the Bank follows an exchange rate targeting policy, rather it seems that the exchange rate is an element of a wider set of indicators that the Eurosystem analyses to evaluate the overall outlook for price developments in the medium term. Indeed, on 7 May 1999 Issing declared "An exchange rate target would, in effect, limit our options in conducting monetary policy aimed at internal price stability. (...) Given the primary objective of the single monetary policy and exchange rate policy to maintain price stability, it would be counterproductive and confusing also to aim at a specific exchange rate".

The ECB has a characteristic two-pillar strategy (cf. Monthly Bulletin, January 1999 and November 2000), where the monitoring of monetary aggregates growth has a prominent role in the assessment of inflationary risks. In particular, the ECB has a reference value of $4.5 \%$ per annum for M3 growth (ECB, 1999 and 1998a). Therefore, although many monetary and financial variables are listed in Table 1, we should expect the ECB to respond to any deviation of M3 growth, $g M 3$, from its target value. However, on 8 May 2003 the Governing Council announced a revision of its monetary policy strategy (ECB, 2003). In that occasion, its chief economist Otmar Issing declared that "Money [is just useful as a] cross-check for longerterm evaluation of monetary stance", with the primary objective of the ECB being only price stability.

By including energy prices, gPOil, we may infer the extent to which Governing Council members expect second round effects from oil price changes, especially taking into account the labour rigidities in mainland Europe.

Finally, to take into account the recent liquidity problems, triggered by the lending and credit crisis in the subprime industry, we consider a proxy for financial market risks, Risk, the spread between the threemonth Euribor rate and the three-month Eurepo rate (i.e. a benchmark interest rate for secured money market transactions in the euro area).

\subsection{Measuring the tone and of central bank announcements}

Since its inception, the ECB has paid considerable attention to its announcement policy, and especially to its choices of medium, form and content. In order to communicate with the public effectively, and address the informational needs of various target groups such as politicians, academics, the press, and participants in the financial markets, the ECB uses various instruments. These include the Monthly Bulletin, the President's monthly press conference (and its Questions and Answers session), the Testimony to the Committee on Monetary Affairs of the European Parliament (which currently takes place four times per 
year) and frequent speeches by its President and / or members of the Governing Council. The present paper focuses on the ECB President's introductory statement to the monthly press conference because the press conference represents "the principal vehicle of the ECB's communication" (ECB, 2007), and it reflects the views of all members of the ECB Governing Council.

To measure central bank communication, we follow Rosa and Verga $(2008,2007)$ and convert each press conference into a wording indicator variable, Index, on a five-value scale from -2 (very dovish) to +2 (very hawkish). The value of zero suggests that the current level of the policy rate is appropriate to maintain price stability over the medium term. The value -1 characterizes an easing period: it is possible that the Repo rate will be cut in the near future. The value -2 indicates that the Governing Council is increasingly inclined to cut interest rates. On the other hand, the values $+1(+2)$ characterizes a (strong) likelihood of future monetary policy tightening. This number, Index, intends to summarize the monetary authority's overall policy stance as communicated by its monetary policy committee (see Rosa and Verga, 2008, and Rosa, 2008, for further details on the coding methodology; the values of Index are available in a separate Appendix). ${ }^{7}$ In some occasions the ECB either did not hold a press conference ( 8 cases, every August until 2005 and January 2001) or held two press conferences in the same month (3 cases, March 2000, October 2000 and June 2001). We treat the missing data problem by employing the value of Index of the preceding month. In months with two press conferences we use the Index of the second conference as it is more up-todate and thus more relevant for the future policy rate decisions.

\section{Econometric results}

\subsection{Estimates (in-sample)}

Table 2 reports the coefficient estimates of the ordered probit model outlined in Equations (2) and (3), together with its limit points $c$ s, for the sample period February 1999 - December 2007, using different information sets and where the dependent variable is the direction of the next most likely ECB policy rate change.

[Insert Table 2 about here]

In the interest of brevity, we summarize the most interesting findings instead of commenting all the regressions individually. As a baseline model, we start by studying the ECB reaction function using standard

\footnotetext{
7 The seminal paper of Romer and Romer (1989) pioneered this so called narrative approach. In particular, they examined the records of Federal Reserve policy deliberations in order to identify exogenous (according to their claim) monetary policy shocks. More generally, the classification of statements is often referred to as content analysis (see Krippendorf, 2004): it consists of a set of techniques to extract the content of a message. A similar methodology for the classification of monetary policy statements is also applied, though this list is by no means exhaustive, by Ehrmann and Fratzscher (2007), Guthrie and Wright (2000) and Jansen and De Haan (2005).
} 
Taylor-type macroeconomic variables, such as inflation and output gap. First, the standard Taylor rule does a poor job in explaining the ECB interest rate setting behavior, as shown by the low pseudo- $\mathrm{R}^{2}$ of Columns 13. Second, the inflation coefficient is never statistically different from zero. Third, the smoothing parameter, i.e. the coefficient of the lagged policy rate, in all but one case is not statistically different from one, which is very large compared to the existing literature on reaction functions, and suggests that the policy rate follows a random walk process. Finally, the coefficient of the output gap is always positive and statistically significant.

The bottom part of Table 2 investigates the degree of the ECB policy rate smoothing by applying a Wald test of the symmetry of the threshold levels across increases and decreases of policy rates. In general, we cannot reject the null hypothesis of symmetry. This evidence suggests that the (non-linear) ordered probit model does not add a dimension of sluggishness to the response of the policy rate to macroeconomic fundamentals beyond the lagged policy rate included in the specification of Equation (2). Finally, the null hypothesis of no first-order serial correlation in the residuals cannot be rejected, and since the result holds for all models considered in this paper is not discussed further: including the lagged policy rate $i_{t-1}$ as explanatory variable is sufficient to guarantee uncorrelated residuals.

Table 2 (Columns 4-6) displays the estimates of the ECB's empirical reaction function using Factor as indicator of economic activity rather than the output gap. The explanatory power, measured by the pseudo- $\mathrm{R}^{2}$, is much higher - more than double - than the corresponding one shown in Table 2. The coefficient on the lagged policy rate is smaller than one, indicating that the observed policy rate follows a stationary process. Second, the coefficients of the inflation variables are positive and marginally statistically significant. The importance of the output gap as explanatory variable completely disappears once Factor is included in the specification. This last finding is in line with the seminal work of Orphanides and van Norden (2002): given the end-of-sample estimation problem, real time estimates of the output gap are fairly unreliable irrespective of the de-trending methodology applied. The interpretation of the above results is as follows. In order to stabilize the economy, central bankers need some measures of the business cycle. Moreover, because of the lags of the monetary transmission mechanism, these measures are needed well in advance. Hence, the members of the ECB Governing Council have to infer the output gap or even actual output from a range of other observable variables, such as survey data. This implies that the policy rate will be correlated with all the indicators the ECB has used in its filtering problem.

Table 2 (Columns 7-8) reports the estimates of the augmented reaction function and analyze whether and to what extent the ECB reacts to exchange rates, monetary aggregates growth, and energy prices. We find that the regressor coefficient of M3 growth is positive and in one case marginally significant at the $10 \%$ level. This finding suggests that the ECB weakly reacts to the dynamics of monetary aggregates. Second, energy prices never enter significantly in the ECB reaction function, indicating that during the sample under consideration changes in oil prices never materialize in permanent changes - second round effects - in wages 
and goods prices. Third, the coefficient of the exchange rate is negative and statistically significant. A depreciation of the euro (i.e. a negative value of $g E$ ) implies a tighter monetary policy, and appears to be a leading indicator of future inflationary risks,

To sum up, the ECB seems to use a wide variety of information to set its policy rate. In particular, survey data, core inflation measures, and exchange rates are economically and statistically significant to explain its interest rate setting behavior. Nevertheless, the results discussed above raise one set of questions. Does the forecasting ability of directional changes in ECB future monetary policy improve with the use of supplementary information compared to standard Taylor-type macroeconomic variables? In particular, how well do these models predict the Governing Council's interest rate decisions? Furthermore, does the inclusion of the wording indicator and the proxy of recent financial turbulence as explanatory variables improve the accuracy of the predictions? We address these questions in the next subsection where we construct both in-sample and out-of-sample predictions for one-, two-, and three-month ahead directional changes in the ECB policy rate.

\subsection{Assessing the models (out-of-sample)}

In the interest of brevity, to compare the predictive ability of the direction of policy rate changes we discuss the corrected predictions and Henriksson and Merton (1981) criterion only for the out-of-sample forecasting exercise. ${ }^{8}$ More specifically, to construct out-of-sample predictions of the next directional change we employ the expanding window method by computing the one-step ahead prediction of the sign of the policy rate change in time $t+1$ by using information available up to time $t$. The starting date of the sample is fixed at February 1999. Every successive observation starting in January 2004 is included in the initialization sample one at a time prior to the forecast of the next one-step ahead prediction of the directional change. Table 3 displays the percentage of corrected classification and the $H M$ values for different specifications of the ECB reaction function reported in the previous subsection (see Table 2), and for three different forecasting horizons (one-, two- and three-month ahead predictions). Interestingly, for all forecasting horizons the Taylor-type specification (i.e. using inflation and output output gap) has always the lowest $H M$ criterion, and can outperform a random walk predictor only for two- and three-month ahead forecasts.

[Insert Table 3 about here]

\footnotetext{
${ }^{8}$ In-sample results are available in a separate Appendix and the contingency tables upon request. We simply note that all the conclusions discussed for the out-of-sample forecasting exercise continue to hold in the in-sample analysis. In particular, the use of wide information sets is crucially important to make more accurate prediction of the future direction of policy rate changes. Moreover, for all specifications and all forecasting horizons there are no large forecasting errors (the predictions never suggest a future increase in the policy rate when the actual movement was downward or vice versa).
} 
The inclusion of the wording indicator, Index, as explanatory variable substantially increase the accuracy of the forecasts, especially for the two- and three-month ahead predictions. This finding indicates that ECB rhetoric allows a better understanding of its policy reaction function, and its statements complement the information contained in actual macro figures such as inflation and economic activity. In other words, central bank communication is helpful to understand how the bank processes and reacts to actual macroeconomic data. The inclusion of the variable Risk also contributes to slightly improve the forecasting ability of the empirical policy function. This result confirms empirically that the ECB reacted to the recent turbulence in financial markets not only by injecting liquidity in the European economy but also by setting its policy rate according to the intensity of the financial crisis.

Finally, there is some evidence that it is easier to predict the overall two- and three-month ahead policy decisions compared to the next-month policy rate change. This finding shows that the ECB has been very effective in securing medium-term predictability. On the other hand, the ECB has been slightly less successful in enhancing short-term predictability about its near-future policy actions. To put it differently, the ECB has been able to educate the public to anticipate the broader future direction of its monetary policy, but has been less successful in signaling the exact timing of rate changes (i.e. advancement or postponement of a more-or-less inevitable change in monetary policy).

\section{Conclusions}

Although a Taylor rule is a standard and popular tool for evaluating monetary policy decisions, its mechanical application could lead to serious pitfalls and to an inadequate explanation of the central bank's interest rate setting behavior. By estimating several instrument policy reaction functions for the ECB this paper sheds some light on actual monetary policy in the euro area for the sample period 1999-2006.

The monetary authority operates under considerable uncertainty about the state of the economy. Moreover, as noted among others by Duisenberg (1999), "monetary policy measures only have an impact on prices with long, variable and not entirely predictable time-lags of between 1.5 and 2 years". Therefore, to identify the existence of potential risks to price stability, the central banker has to solve a signal-extraction problem using information from many different variables (Svensson and Woodford, 2003). In other words, the monetary authority has to infer the future inflation from a set of observable variables. Obviously, the indicators the ECB uses in its filtering problem will be correlated with its policy rate. The value added of this study to the empirical monetary policy literature consists of highlighting the importance of using wide information sets that includes ECB words to predict its future monetary policy decisions. More specifically, we find that the real-time estimate of the output gap is not significant in its reaction function once we control for survey data. Second, core inflation measures of price stability better explain the ECB's actions compared to headline inflation. Third, the inclusion of the euro exchange rate with the U.S. dollar and monetary 
aggregates substantially increase the accuracy of the prediction of the direction of future ECB policy rate change both in-sample and out-of-sample. Interestingly, the tone of ECB statements provides complementary, rather than substitutable, pieces of information with respect to macroeconomic variables. Finally, there is some evidence that the ECB has been fairly successful in educating the public to anticipate the broader future direction of its monetary policy, but has been less successful in signaling the exact timing of rate changes (i.e. advancement or postponement of a more-or-less inevitable change in monetary policy). 


\section{References}

Ball, L., 1999. Policy rules for open economies. In Taylor J. (ed.) (1999), Monetary policy rules, University of Chicago Press.

Batini, N., Harrison, R., Millard, S.P., 2001. Monetary policy rules for an open economy. Bank of England WP 149.

Baxter, M., King, R.G., 1999. Measuring business cycles: approximate band-pass filters for economic time series. Review of Economics and Statistics, 81(4), 575-593.

Blinder, A. S., Ehrmann, M., Fratzscher, M., De Haan, J., Jansen, J. 2008. Central bank communication and monetary policy: a survey of theory and evidence, Journal of Economic Literature, forthcoming.

Carstensen, K., 2006. Estimating the ECB policy reaction function. German Economic Review, 7 (1), 1-34.

Carstensen, K., Colavecchio, R., 2006. Did the revision of the ECB monetary policy strategy affect the reaction function? Rivista Italiana degli Economisti, 1 (3), 51-86

Cerra, V., Saxena, S. C., 2000. Alternative methods of estimating potential output and output gap: an application to Sweden. IMF Working Paper 00/59.

Chow, G., Lin, A., 1971. Best linear unbiased interpolation, distribution and extrapolation of time series by related time series. Review of Economic and Statistics, 53(4), 372-375.

Clarida, R., Gali, J., Gertler, M., 2000. Monetary policy rules and macroeconomic stability: theory and evidence. Quarterly Journal of Economics, 115, 147-180.

Clarida, R., Gali, J., Gertler, M., 1998. Monetary policy rules in practice. Some international evidence. European Economic Review, 42, 1033-1067.

Coenen, G., Levin, A., Wieland, V., 2005. Data uncertainty and the role of money as an information variable for monetary policy. European Economic Review, 49(4), 975-1006.

Davutyan, N., Parke, W., 1995. The operations of the Bank of England 1890-1908: a dynamic probit approach. Journal of Money, Credit, and Banking. 27(4), 1099-1112.

Duisenberg, W. F., 1999. Speech at the National Bank of Poland, Warsaw, Poland, 4 May.

ECB, 2007. Communicating monetary policy to financial markets. ECB Monthly Bulletin, April.

ECB, 2003. The ECB's monetary policy strategy. Press Release, 8 May 2003.

ECB, 1999. Review of the quantitative reference value for monetary growth. Press release, 2 December.

ECB, 1998a. The quantitative reference value for monetary growth. Press release, 1 December.

ECB, 1998b. A stability-oriented monetary policy strategy for the ESCB. Press release, 13 October.

ECB, Monthly Bulletin, all issues from January 1999 to December 2007.

Ehrmann, M., Fratzscher, M., 2007a. Communication and decision-making by central bank committees: different strategies, same effectiveness? Journal of Money, Credit and Banking, 39(2-3), 509-41. 
Eichengreen, B., Watson, B.W., Grossman, R.S., 1985. Bank rate policy under the interwar Gold Standard: A dynamic probit model. Economic Journal 95, 725-745.

Fourçans, A., Vranceanu, R., 2004. The ECB interest rate rule under the Duisenberg presidency. European Journal of Political Economy, 20, 579-595.

Gerdesmeier, D., Roffia, B., 2003. Empirical estimates of reaction functions for the euro area. ECB Working Paper 206.

Gerlach-Kristen, P., 2003. Interest rate reaction functions and the Taylor rule in the euro area, ECB Working Paper 258.

Gerlach, S., 2007. Interest rate setting by the ECB 1999-2006: Words and deeds. International Journal of Central Banking, 3(3), 1-45.

Gerlach, S., Schnabel, G., 2000. The Taylor rule and interest rates in the EMU area. Economics Letters, 67(2), 165-171.

Gourieroux, C., Monfort, A., Trognon, A., 1985. A general approach to serial correlation. Econometric Theory, 1 (3), 315-340.

Guthrie, G., Wright, J., 2000. Open Mouth Operations. Journal of Monetary Economics, 46, 489-516

Heinemann, F., Ullrich, K., 2007. Does it pay to watch central bankers' lips? The information content of ECB wording. Swiss Journal of Economics and Statistics, 143 (2), 155-185

Henriksson, R.D., Merton, R.C., 1981. On market timing and investment performance. II. Statistical procedures for evaluating forecasting skills. Journal of Business, 54 (4), 513-533.

Hodrick, R.J., Prescott, E., 1997. Post-war U.S. business cycles: an empirical investigation. Journal of Money, Credit and Banking, 29, 1-16.

Jansen, D., De Haan, J., 2008. Has ECB communication been helpful in predicting interest rate decisions? An evaluation of the early years of the Economic and Monetary Union., Applied Economics, forthcoming.

Jansen, D.-J., de Haan, J., 2005. Talking heads: the effects of ECB statements on the euro-dollar exchange rate. Journal of International Money and Finance 24, 343-361.

Krippendorf, K., 2004. Content analysis: an introduction to its methodology. 2nd edition, Thousand Oaks, CA: Sage.

Orphanides, A., van Norden, S., 2002. The unreliability of output-gap estimates in real time. Review of Economics and Statistics, 84 (4), 569-583.

Orphanides, A., 2001. Monetary policy rules based on real-time data. American Economic Review, 91(4), 964-985.

Romer, C., Romer, D., 1989. Does monetary policy matter? A new test in the spirit of Friedman and Schwartz. NBER Macroeconomics Annual, 121-170.

Rosa, C., 2008. Talking less and moving the market more: is this the recipe for monetary policy effectiveness? Evidence from the ECB and the Fed. Centre for Economic Performance Discussion Paper 855. 
Rosa, C., Verga, G., 2008. The impact of central bank announcements on asset prices in real time. International Journal of Central Banking, 4 (2), 175-217

Rosa, C., Verga, G., 2007. On the consistency and effectiveness of central bank communication: evidence from the ECB. European Journal of Political Economy, 23, 146-175.

Ruud, P.A., 2000. Introduction to classical econometric theory, Oxford University Press.

Sauer, S., Sturm, J.-E., 2007. Using Taylor rules to understand ECB monetary policy. German Economic Review, 8 (3), 375-398.

Svensson, L.E.O., Woodford, M., 2003. Indicator variables for optimal policy. Journal of Monetary Economics, 50, 691-720.

Taylor, J., 2001. The role of the exchange rate in monetary policy rules. American Economic Review, 91, 263-267.

Taylor, J., 1993. Discretion versus policy rules in practice. Carnegie-Rochester Conference Series on Public Policy, 39, 195-214.

Ullrich, K., 2003. A comparison between the Fed and the ECB: Taylor rules. ZEW Discussion Paper 03-19.

Vanderhart, P.G., 2000. The Federal Reserve's reaction function under Greenspan: An ordinal probit analysis. Journal of Macroeconomics, 22(4), 631-644.

Woodford, M., 2003. Interest and prices: foundations of a theory of monetary policy. Princeton University Press. 
Table 1 - Changes in the ECB policy rate

\begin{tabular}{cc}
$\Delta i_{t+1}$ & Count \\
\hline-0.50 & 5 \\
-0.25 & 3 \\
No change & 84 \\
+0.25 & 13 \\
+0.50 & 2 \\
\hline Total & 107 \\
\hline \hline
\end{tabular}

NOTE: The sample is February 1999 - December 2007. 


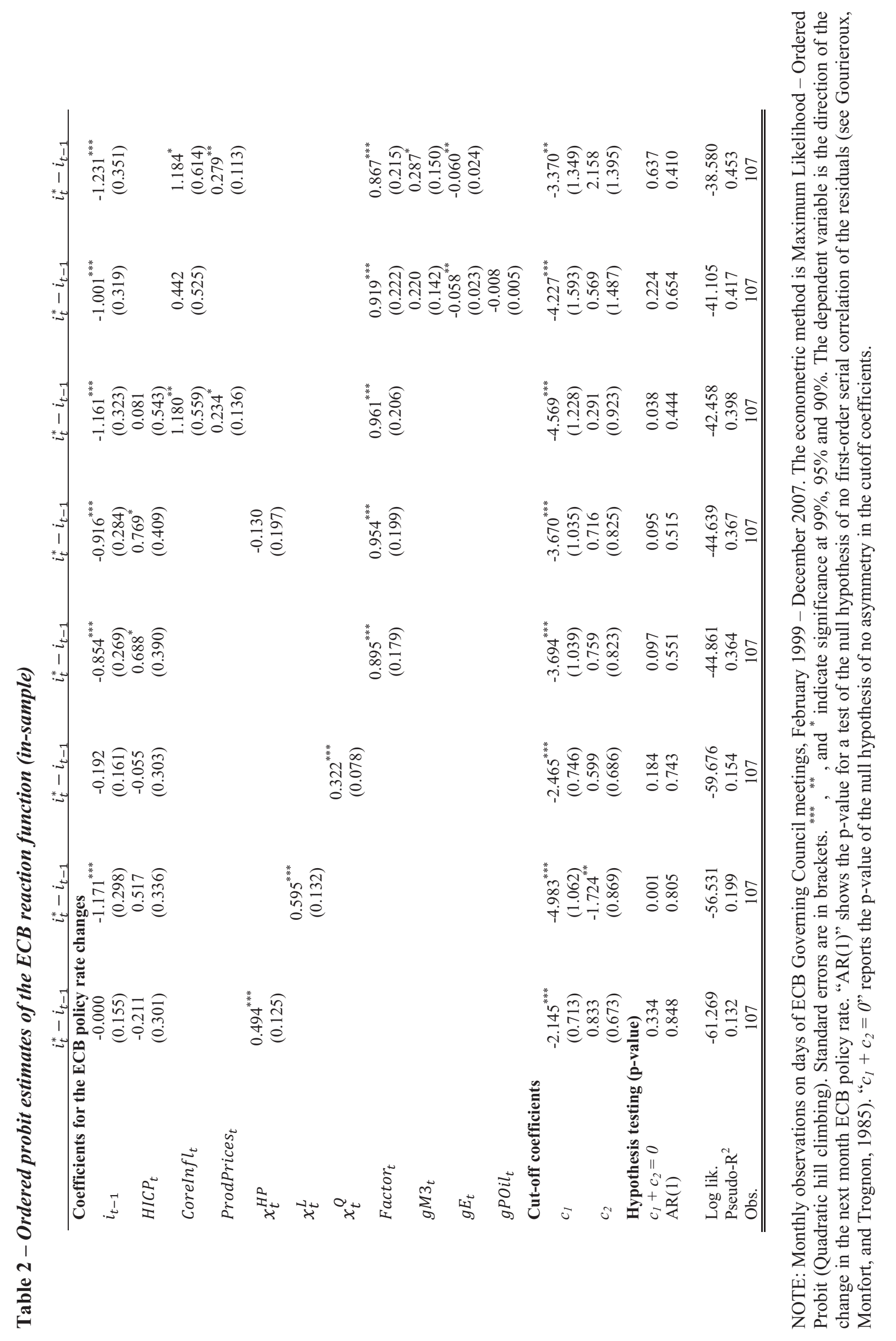




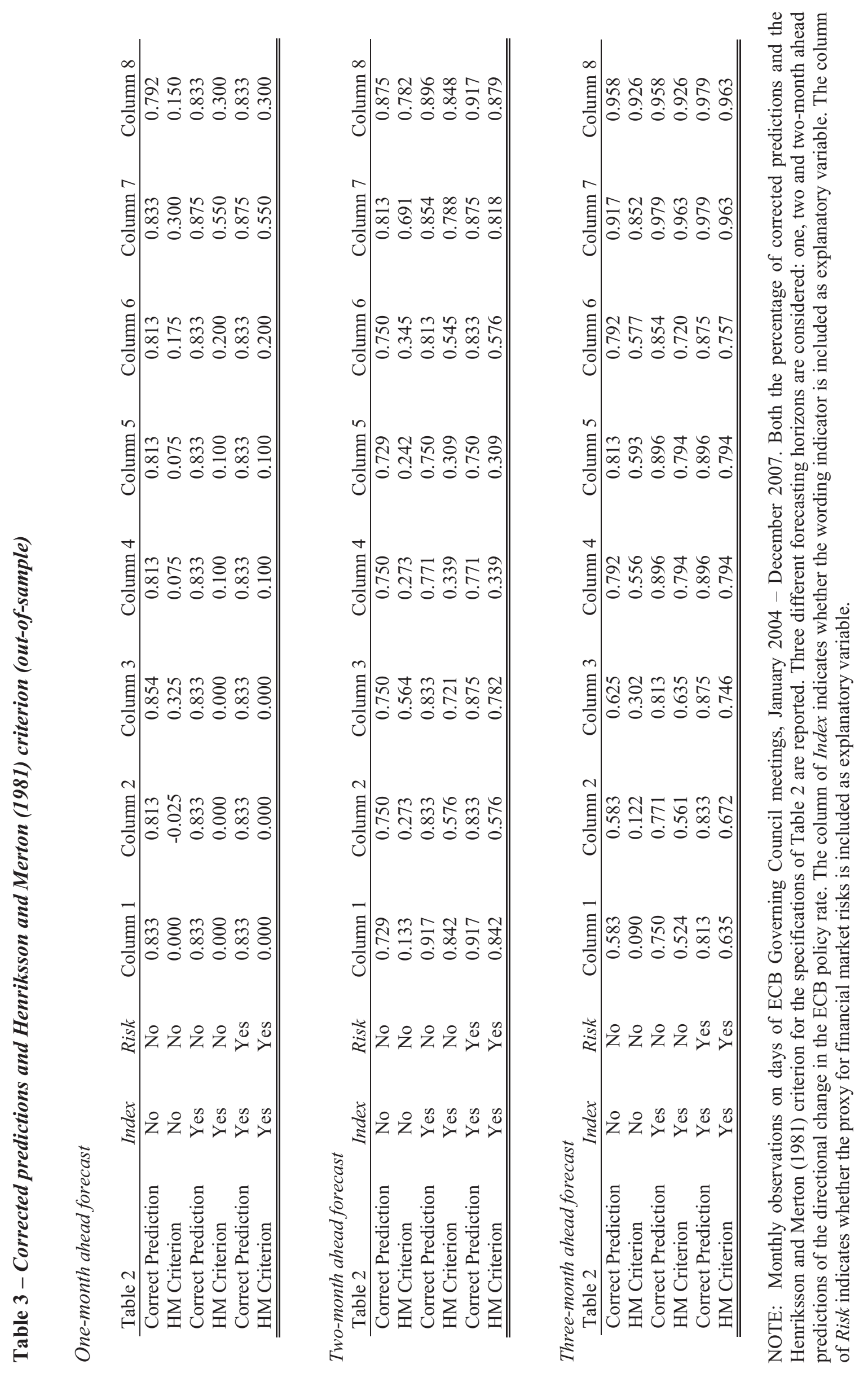


Figure 1 - Real economic activity indicators

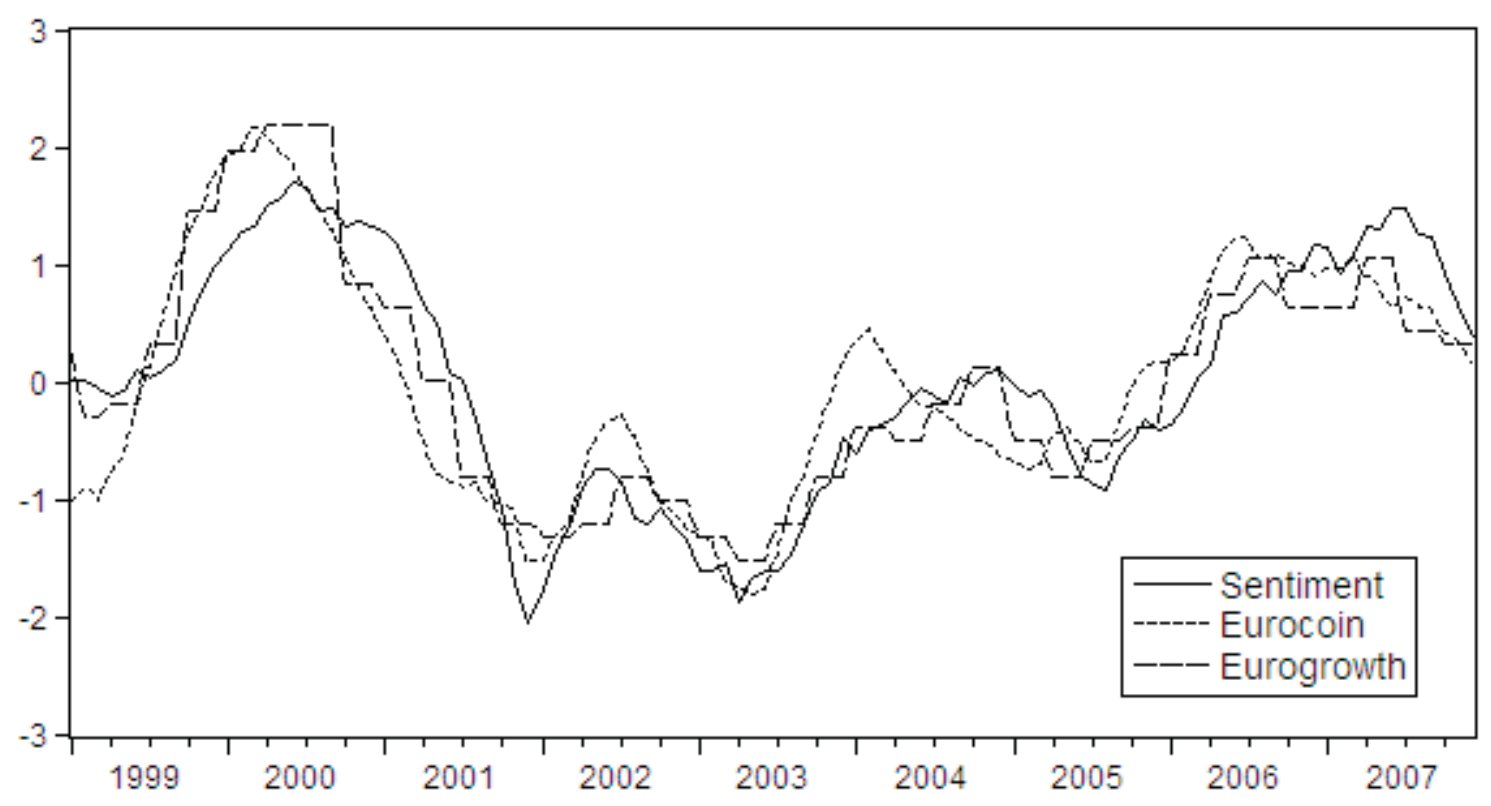

NOTE: The chart displays the standardized Sentiment (solid line), Eurocoin (dotted line) and Eurogrowth (dashed line) survey indicators. The sample is from January 1999 to December 2007. 


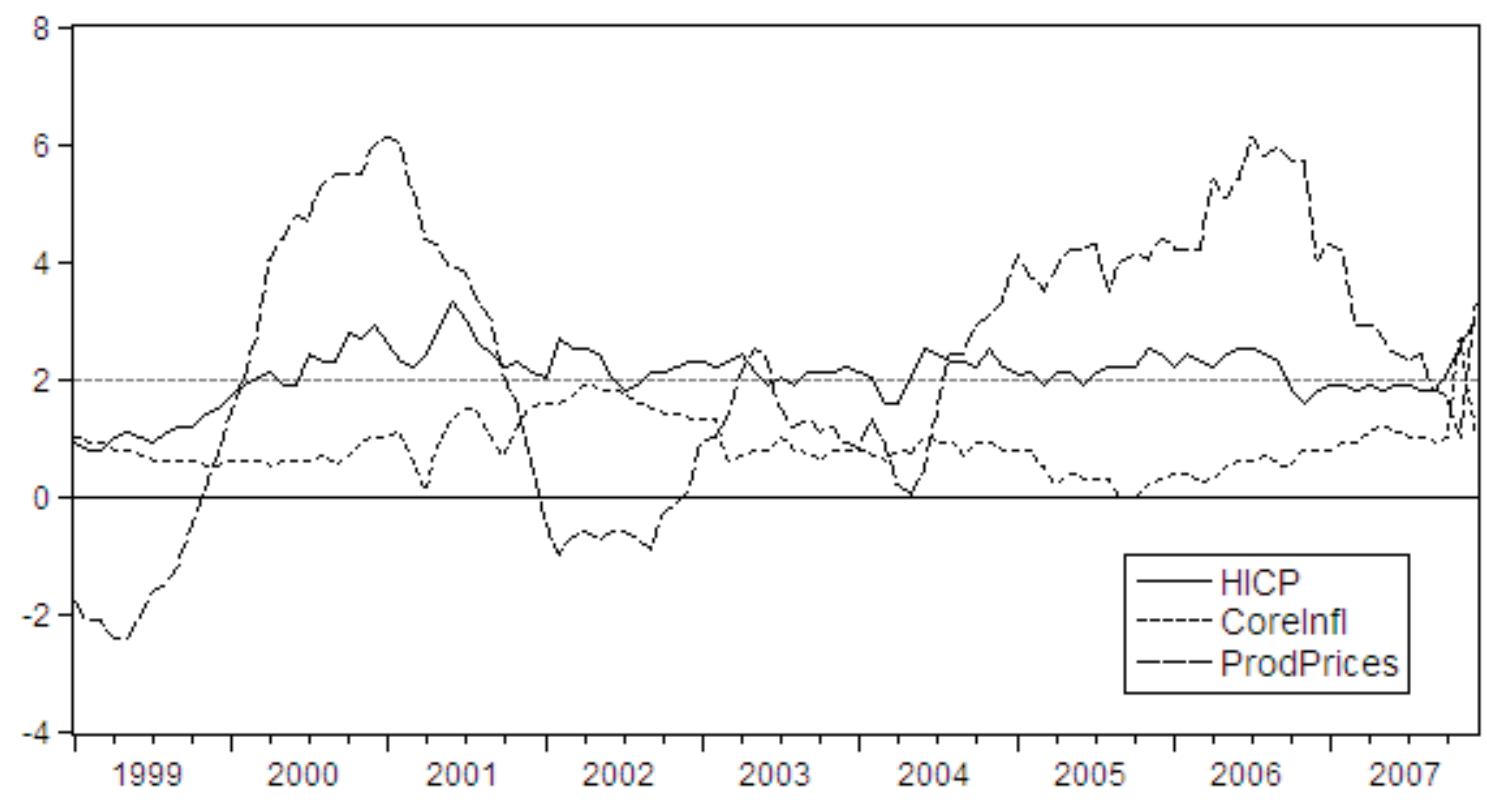

NOTE: The chart displays the HICP (solid line), the HICP excluding food and energy prices (CoreInfl, dotted line), and industrial producer prices (ProdPrices, dashed line). The sample is from January 1999 to December 2007. 


\section{Recent titles}

\section{CORE Discussion Papers}

2008/46. Joe THARAKAN and Jean-Philippe TROPEANO. On the impact of labor market matching on regional disparities.

2008/47. Shin-Huei WANG and Cheng HSIAO. An easy test for two stationary long processes being uncorrelated via AR approximations.

2008/48. David DE LA CROIX. Adult longevity and economic take-off: from Malthus to Ben-Porath.

2008/49. David DE LA CROIX and Gregory PONTHIERE. On the Golden Rule of capital accumulation under endogenous longevity.

2008/50. Jean J. GABSZEWICZ and Skerdilajda ZANAJ. Successive oligopolies and decreasing returns.

2008/51. Marie-Louise LEROUX, Pierre PESTIEAU and Grégory PONTHIERE. Optimal linear taxation under endogenous longevity.

2008/52. Yuri YATSENKO, Raouf BOUCEKKINE and Natali HRITONENKO. Estimating the dynamics of R\&D-based growth models.

2008/53. Roland Iwan LUTTENS and Marie-Anne VALFORT. Voting for redistribution under desertsensitive altruism.

2008/54. Sergei PEKARSKI. Budget deficits and inflation feedback. 2008/55. Raouf BOUCEKKINE, Jacek B. KRAWCZYK and Thomas VALLEE. Towards an understanding of tradeoffs between regional wealth, tightness of a common environmental constraint and the sharing rules.

2008/56. Santanu S. DEY. A note on the split rank of intersection cuts.

2008/57. Yu. NESTEROV. Primal-dual interior-point methods with asymmetric barriers.

2008/58. Marie-Louise LEROUX, Pierre PESTIEAU and Gregory PONTHIERE. Should we subsidize longevity?

2008/59. J. Roderick McCRORIE. The role of Skorokhod space in the development of the econometric analysis of time series.

2008/60. Yu. NESTEROV. Barrier subgradient method.

2008/61. Thierry BRECHET, Johan EYCKMANS, François GERARD, Philippe MARBAIX, Henry TULKENS and Jean-Pascal VAN YPERSELE. The impact of the unilateral EU commitment on the stability of international climate agreements.

2008/62. Giorgia OGGIONI and Yves SMEERS. Average power contracts can mitigate carbon leakage.

2008/63. Jean-Sébastien TANCREZ, Philippe CHEVALIER and Pierre SEMAL. A tight bound on the throughput of queueing networks with blocking.

2008/64. Nicolas GILLIS and François GLINEUR. Nonnegative factorization and the maximum edge biclique problem.

2008/65. Geir B. ASHEIM, Claude D'ASPREMONT and Kuntal BANERJEE. Generalized timeinvariant overtaking.

2008/66. Jean-François CAULIER, Ana MAULEON and Vincent VANNETELBOSCH. Contractually stable networks.

2008/67. Jean J. GABSZEWICZ, Filomena GARCIA, Joana PAIS and Joana RESENDE. On Gale and Shapley 'College admissions and stability of marriage'.

2008/68. Axel GAUTIER and Anne YVRANDE-BILLON. Contract renewal as an incentive device. An application to the French urban public transport sector.

2008/69. Yuri YATSENKO and Natali HRITONENKO. Discrete-continuous analysis of optimal equipment replacement.

2008/70. Michel JOURNÉE, Yurii NESTEROV, Peter RICHTÁRIK and Rodolphe SEPULCHRE. Generalized power method for sparse principal component analysis.

2008/71. Toshihiro OKUBO and Pierre M. PICARD. Firms' location under taste and demand heterogeneity.

2008/72. Iwan MEIER and Jeroen V.K. ROMBOUTS. Style rotation and performance persistence of mutual funds.

2008/73. Shin-Huei WANG and Christian M. HAFNER. Estimating autocorrelations in the presence of deterministic trends. 


\section{Recent titles}

\section{CORE Discussion Papers - continued}

2008/74. Yuri YATSENKO and Natali HRITONENKO. Technological breakthroughs and asset replacement.

2008/75. Julio DÁVILA. The taxation of capital returns in overlapping generations economies without financial assets.

2008/76. Giorgia OGGIONI and Yves SMEERS. Equilibrium models for the carbon leakage problem.

2008/77. Jean-François MERTENS and Anna RUBINCHIK. Intergenerational equity and the discount rate for cost-benefit analysis.

2008/78. Claire DUJARDIN and Florence GOFFETTE-NAGOT. Does public housing occupancy increase unemployment?

2008/79. Sandra PONCET, Walter STEINGRESS and Hylke VANDENBUSSCHE. Financial constraints in China: firm-level evidence.

2008/80. Jean GABSZEWICZ, Salome GVETADZE, Didier LAUSSEL and Patrice PIERETTI. Pubic goods' attractiveness and migrations.

2008/81. Karen CRABBE and Hylke VANDENBUSSCHE. Are your firm's taxes set in Warsaw? Spatial tax competition in Europe.

2008/82. Jean-Sébastien TANCREZ, Benoît ROLAND, Jean-Philippe CORDIER and Fouad RIANE. How stochasticity and emergencies disrupt the surgical schedule.

2008/83. Peter RICHTÁRIK. Approximate level method.

2008/84. Çağatay KAYI and Eve RAMAEKERS. Characterizations of Pareto-efficient, fair, and strategyproof allocation rules in queueing problems.

2009/1. Carlo ROSA. Forecasting the direction of policy rate changes: The importance of ECB words.

\section{Books}

Y. POCHET and L. WOLSEY (eds.) (2006), Production planning by mixed integer programming. New York, Springer-Verlag.

P. PESTIEAU (ed.) (2006), The welfare state in the European Union: economic and social perspectives. Oxford, Oxford University Press.

H. TULKENS (ed.) (2006), Public goods, environmental externalities and fiscal competition. New York, Springer-Verlag.

V. GINSBURGH and D. THROSBY (eds.) (2006), Handbook of the economics of art and culture. Amsterdam, Elsevier.

J. GABSZEWICZ (ed.) (2006), La différenciation des produits. Paris, La découverte.

L. BAUWENS, W. POHLMEIER and D. VEREDAS (eds.) (2008), High frequency financial econometrics: recent developments. Heidelberg, Physica-Verlag.

P. VAN HENTENRYCKE and L. WOLSEY (eds.) (2007), Integration of AI and OR techniques in constraint programming for combinatorial optimization problems. Berlin, Springer.

\section{CORE Lecture Series}

C. GOURIÉROUX and A. MONFORT (1995), Simulation Based Econometric Methods.

A. RUBINSTEIN (1996), Lectures on Modeling Bounded Rationality.

J. RENEGAR (1999), A Mathematical View of Interior-Point Methods in Convex Optimization.

B.D. BERNHEIM and M.D. WHINSTON (1999), Anticompetitive Exclusion and Foreclosure Through Vertical Agreements.

D. BIENSTOCK (2001), Potential function methods for approximately solving linear programming problems: theory and practice.

R. AMIR (2002), Supermodularity and complementarity in economics.

R. WEISMANTEL (2006), Lectures on mixed nonlinear programming. 